\title{
Single-cell elastography: Probing for disease with the atomic force microscope
}

\author{
Kevin D. Costa* \\ Department of Biomedical Engineering, Columbia University, New York, NY 10027, USA
}

\begin{abstract}
The atomic force microscope (AFM) is emerging as a powerful tool in cell biology. Originally developed for highresolution imaging purposes, the AFM also has unique capabilities as a nano-indenter to probe the dynamic viscoelastic material properties of living cells in culture. In particular, AFM elastography combines imaging and indentation modalities to map the spatial distribution of cell mechanical properties, which in turn reflect the structure and function of the underlying cytoskeleton. Such measurements have contributed to our understanding of cell mechanics and cell biology and appear to be sensitive to the presence of disease in individual cells. This chapter provides a background on the principles and practice of AFM elastography and reviews the literature comparing cell mechanics in normal and diseased states, making a case for the use of such measurements as disease markers. Emphasis is placed on the need for more comprehensive and detailed quantification of cell biomechanical properties beyond the current standard methods of analysis. A number of technical and practical hurdles have yet to be overcome before the method can be of clinical use. However, the future holds great promise for AFM elastography of living cells to provide novel biomechanical markers that will enhance the detection, diagnosis, and treatment of disease.
\end{abstract}

Keywords: Cell biomechanics, viscoelasticity, cytoskeleton, indentation, stiffness, disease markers

\section{Introduction}

Many physiologic and pathophysiologic processes alter the biomechanical properties of the tissues they affect. It is well known that muscles get harder with weight training, and skin becomes less resilient with age. Abnormal tissue biomechanics also play a key role in a wide range of diseases such as osteoporosis, osteoarthritis, cystic fibrosis, muscular dystrophy, ventricular aneurysm, and others. Based on the relationship between tissue mechanics and pathology, palpation is used clinically to detect stiff nodules associated with breast cancer and abdominal hardness due to cirrhosis of the liver. In an effort to make such examinations more quantitative, a number of indentation devices have been developed to evaluate the stiffness

*Address for correspondence: Kevin D. Costa, Ph.D., Columbia University, Department of Biomedical Engineering, 351 Engineering Terrace, Mail Code 8904, 1210 Amsterdam Avenue, New York, NY 10027, USA. Tel.: +1 212854 9163; Fax: +1 212854 8725; E-mail: kdc17@columbia.edu of soft tissues in vivo [1-4], though these have yet to achieve wide clinical acceptance.

Recently, there has been great interest in a new technique known as elastography [5], which generally refers to any imaging modality that yields information about the mechanical properties of a tissue. Based primarily on ultrasound and magnetic resonance imaging methods, elastographic techniques have demonstrated the ability to detect the size and shape of tumors [5, $6]$, to identify regional anatomic differences in normal tissue stiffness [5,6], to identify abnormal cardiac deformation due to coronary artery disease $[7,8]$, and even have been implemented in a catheter system for intravascular evaluation of atherosclerotic plaques [9]. However, in an elastogram, image contrast is based on regional differences in the response of tissue structures to applied loads, yielding new information not available using traditional medical imaging modalities. Consequently, there is rapidly growing clinical interest in the ability to diagnose disease based on analysis and visualization of regional tissue mechanical properties.

It follows that pathophysiologic changes in the mechanical properties of tissues may be manifest at the 
single cell level. In fact, alterations of cell mechanical properties recently have been reported in certain forms of cancer, arthritis, and cardiovascular disease [1013], opening a new window to examine the underlying mechanisms of these pathologies. Moreover, once the normal and abnormal mechanical properties of a given cell type are established, it is enticing to imagine that potential pharmaceutical or genetic treatments might be evaluated by measuring their effects on the mechanical properties of target cells in vitro. Hence, by complementing other evolving single-cell analysis techniques $[14,15]$, the identification of a distinct biomechanical fingerprint of the cell in response to a battery of material tests may offer an important new approach in cell biology. Single cell elastography using atomic force microscopy is a technique with the potential to identify such a mechanical fingerprint.

At present, atomic force microscope (AFM) elastography is largely a research tool used by biomedical engineers and biophysicists to study the mechanics of cell function. However, the technique is evolving rapidly to a state where medical applications may be feasible. Therefore, the purpose of this article is to provide a brief introduction to cell biomechanics and its relation to disease; to describe the AFM experiment, including principles of operation and methods of data analysis; to review recent findings in the area of cell mechanics with AFM; and to identify the current limits of the technology and future developments that would enhance transfer to the basic and clinical sciences to aid in the identification of novel cell biomechanical markers that might lead to improved detection, diagnosis, and treatment of disease.

\subsection{Basic cell biomechanics}

Such a detailed characterization of cell mechanics requires knowledge of the constitutive relation of the cell, which relates cell deformation (i.e., strain) to internal forces and externally applied loads (i.e., stress) acting on the cell. Stiffness is defined as the slope of the force-deformation curve - it depends on geometry and hence on the particular sample studied and the testing device used. Therefore, rather than relating force $(F)$ and deformation $(\Delta L)$ directly, it is important to consider the related quantities stress $(\sigma=F / A)$ and strain $\left(\varepsilon=\left(\Delta L / L_{o}\right)\right.$ because these are normalized measures (by area, $A$, and initial length, $L_{o}$, respectively) independent of size or geometry. That is, the stress-strain constitutive relation reflects an underlying property of the cell. Perhaps the best known and sim-

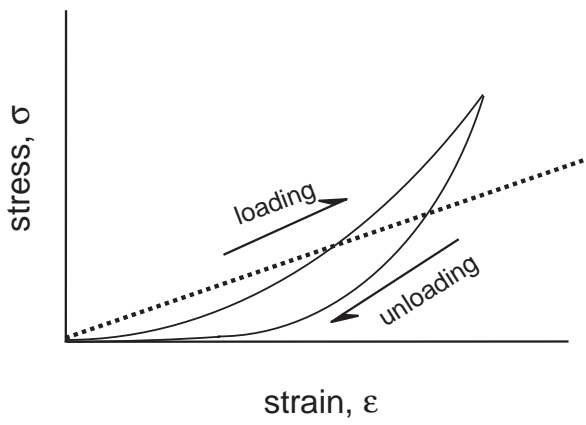

Fig. 1. An idealized linear elastic material (dotted line) is characterized by the Young's modulus obtained from the slope of the stress-strain curve. For most biological soft tissues, the stress-strain relation is nonlinear (solid line) and exhibits viscoelastic hysteresis between loading and unloading segments of the curve.

plest constitutive relation for solid materials is Hooke's law, which states that stress is proportional to strain $(\sigma=E \varepsilon)$, where the constant of proportionality, $E$, is called the Young's modulus. Materials that obey Hooke's law (e.g., rubber, steel, bone) are called linear elastic (Fig. 1). A similar constitutive relation for fluid materials states that the stress is proportional to the rate of strain $(\sigma=: \mu d \varepsilon / d t)$, where the constant of proportionality, $\mu$, is called the viscosity. Such materials (e.g., water, blood plasma) are called Newtonian fluids.

Macroscopically, most soft biological tissues are more complex than these simple idealized materials [16]. In addition to being heterogeneous, with mechanical properties varying from one region of the tissue to another, the stress-strain relationship typically is nonlinear (e.g., polynomial or exponential), such that the modulus increases as the tissue is deformed (Fig. 1). Many tissues also have a preferred structural alignment that gives rise to material anisotropy, such that the measured material properties depend upon the axis along which the tissue is tested. Moreover, most soft tissues are viscoelastic materials consisting of solid and fluid (and ionic) components that influence how the tissue responds to mechanical stimulation $[17,18]$. Hence, the mechanical behavior depends not only on how much the tissue is deformed, but also on how rapidly it is deformed and on the memory of its previous deformation history, resulting in hysteresis between the loading and unloading portions of the stress-strain curve (Fig. 1). Clearly, such tissues are not well characterized by a single Young's modulus, and constitutive equations that combine elastic and viscous properties are required to mathematically model their stress-strain behavior [16].

Single cells appear to share many of the same biomechanical characteristics as macroscopic soft tissues. 
Even the earliest analyses of leukocyte mechanics recognized the importance of viscoelasticity due to the aqueous gel nature of the cytoplasm [19,20]. More recent studies suggest that actin filaments, intermediate filaments, and microtubules each contribute differently to the viscoelastic properties of fibroblasts and endothelial cells [21-23], though the specific roles remain quite controversial [24]. Some anchorage-dependent cells appear to exhibit nonlinear elastic behavior, also called strain hardening [25], but it is unclear whether this is an intrinsic material property or a consequence of the underlying cytoskeletal architecture [26]. Heterogeneity of cell mechanical properties has been associated with the nucleus and other organelles [27,28]. In addition, the major cytoskeletal filaments that determine cell material properties are heterogeneously distributed, preferentially oriented, and dynamic - assembling, disassembling, and reorganizing in response to their mechanical environment [29-32]. Consequently, reported measurements of the Young's modulus of a cell must be interpreted with caution. Unfortunately, relatively little is known about the more detailed multiaxial, nonlinear, viscoelastic mechanical properties of most cells, and the identification of such represents one of the major challenges in modern biomechanics.

\subsection{Cell mechanics as a disease indicator}

Nevertheless, the field of cell mechanics has evolved tremendously in the past two decades, and several texts have now been devoted to the topic [33-35]. Of particular interest here are the growing number of studies that demonstrate a close association between cell mechanical properties and various disease conditions. For example, cultured myotubes from a dystrophin-deficient rat model of Duchenne muscular dystrophy were only one-fourth as stiff as normal cells [36], and recent evidence suggests that some muscle types are protected from dystrophin deficiency by up-regulating specialized accessory proteins that act to preserve cell stiffness [37]. Chondrocytes isolated from osteoarthritic human cartilage exhibit elevated viscoelastic moduli compared to cells from normal tissue [28], which may underlie the dissimilar responses of these cells to external mechanical stimulation [38]. Differences in mechanical properties between normal hepatocytes and hepatocellular carcinoma cells were restricted to the elastic moduli, while the viscous modulus was unaltered [39]. On the other hand, pressure-overload ventricular hypertrophy specifically increases viscous damping (without affecting elastic stiffness) in passive cardiac myocytes [12]. Therefore, methods of elastographic mapping must be developed that are sensitive to changes in viscous as well as elastic properties of the cell. Erythrocytes from patients with sickle cell disease are stiffer and more viscous than are normal red blood cells $[13,40]$. These mechanical properties are restored to near-normal values in patients treated with hydroxyurea $[13,41]$, which suggests that measurements of cell mechanics also may be used to monitor the efficacy of therapeutic interventions.

Because cell mechanical properties are determined largely by the underlying cytoskeleton, any disease process that alters the composition, organization, kinetics, or crosslinking of the cytoskeleton is likely to be detectable using single-cell elastography. At this time, data on the mechanical properties of different cell types are critically needed to establish methodological criteria and guidelines for comparing measured mechanical properties with a normal population, as is being done for clinical hemorheology $[42,43]$. Thus, the development of tools for reliable and rapid characterization of cell mechanical properties is essential.

\subsection{Measurement techniques}

Micropipette aspiration has been used widely to study the mechanical properties of red and white blood cells $[20,44,45]$. Most studies find that the cytoplasm of these cells behaves like a fluid, with elastic properties attributed to the cell membrane and cortical skeleton. This technique applied to endothelial cells subjected to shear stress revealed greater cytoplasmic stiffness compared to non-sheared cells [46]. While variations of the micropipette method continue to provide important information on cells floating in suspension $[11,47]$, these methods are less well suited to studying adherent cells because the large deformation caused by aspiration may disrupt connections between the cell membrane and the underlying cytoskeleton. In addition, due to the large area aspirated, this technique has limited potential for examining regional variations in mechanical properties.

Indentation is an alternative approach for identifying in-plane material properties of biological tissues [48, 49]. Indeed, a “cell poker" utilizing pulled glass microfibers has been used to explore the mechanical properties of living cells $[27,50,51]$. In fibroblasts, stiffness was lower over the nucleus than over the cytoplasm, increased with indentation depth, and decreased after disrupting actin filaments with cytochalasin [27]. However, due to the large size of the probe (diameter $\sim 2 \mu \mathrm{m}$ ) relative to the cell thickness (typically $<5 \mu \mathrm{m}$ ), 
some of these findings may have been influenced by the rigid substrate to which the cells were attached [52].

A number of alternative specialized techniques such as magnetic twisting cytometry [53], laser tracking microrheology [54], magnetic tweezers [55], and the optical stretcher [56], also have been developed to study the mechanical properties of cells with a well-defined cytoskeleton. However, following its invention in 1986 as a high-resolution imaging tool for investigating semiconductor properties at the atomic scale [57], the AFM rapidly has become one of the most versatile and widely used methods for studying mechanical properties of living cells [58].

\section{Fundamentals of atomic force microscopy}

The AFM is well suited for cell mechanics applications due to its high sensitivity (sub-nanoNewton), high spatial resolution (sub-micron), and the ability to be used for real-time measurements in a physiologic aqueous cell culture environment. An important advantage of AFM over other cell mechanics techniques is the ability to combine high-resolution scanning with nano-indentation, which allows direct correlation of local mechanical properties with underlying cytoskeletal structures $[23,59]$. Unlike most other cell imaging techniques, atomic force microscopy is based on a direct mechanical interaction between the probe and the sample. In this sense, the AFM is inherently an elastography instrument. Another advantage is that commercial availability of the AFM makes it accessible to a broad range of investigators.

\subsection{Principles of operation}

In principle, the AFM is a relatively simple instrument that involves laser tracking of the deflection of a microscopic-sized cantilever probe as its tip scans, indents, or otherwise interacts with the sample (Fig. 2). The AFM probe is the transducer of the instrument and typically consists of a rectangular or "V"-shaped cantilever about 100 to 300 microns long and about half a micron thick, microfabricated of silicon or siliconnitride [60]. The physical and geometric properties of the cantilever determine its spring constant, $k$, which is used to convert the measured cantilever deflection, $h$, into a contact force, $F=k \times h$. The value of $k$, which typically ranges from $0.01 \mathrm{~N} / \mathrm{m}$ to $1.0 \mathrm{~N} / \mathrm{m}$ for cell mechanics applications, is nominally provided by the manufacturer and may be individually calibrated using a variety of methods [61-63].

The standard AFM probe has an integrated pyramidshaped tip with a blunted point having a radius of curvature in the 50-100 nanometer range (Fig. 2b). It is this tip that actually comes in contact with the cell, while the cantilever serves as a soft spring to measure the contact force. The tip dimension determines the spatial resolution of the instrument. Therefore, sharpened pyramids, etched silicon cones, carbon nanotubes, and other high-aspect ratio tips have been developed to scan samples with ultra high resolution $[60,64]$. However, such tips have been shown to penetrate the cell membrane and cause damage to living cells, whereas the standard pyramid tip apparently does not penetrate the cell membrane [65]. Cell viability has been demonstrated up to 48 hours after AFM scanning [66,67], although significant alterations of cell morphology and transfer of membrane to the probe tip can occur under some conditions [67-69]. Modified AFM probes with glass or polystyrene microsphere tips also have been used for some cellular applications to yield a more easily characterized tip geometry, though at the expense of decreased spatial resolution [70,71].

The AFM sensor uses a laser beam reflected off the end of the cantilever probe and onto a four-quadrant photodetector to monitor vertical and lateral deflections of the probe due to contact forces at the tip. AFM probes often are coated with a thin layer of gold to increase reflectivity, especially for cell mechanics applications in which the laser intensity may be attenuated by the phenol red present in standard cell culture medium. The distance between the probe and the photodetector amplifies the laser reflection such that movements of the AFM tip on the order of $0.1 \mathrm{~nm}$ can be detected reliably [63].

The actuator that moves the AFM probe in the $\mathrm{z}$ direction toward or away from the sample is a piezoelectric ceramic that deforms in response to applied voltages. The typical z-range is about 6 microns, though custom configurations have achieved a z-range up to about 20 microns [70]. Although piezoelectric materials inherently are nonlinear and hysteretic, these effects can be overcome by software compensation (open-loop design) or direct strain-gauge monitoring (closed-loop design) to yield very precise positioning of the AFM tip with sub-nanometer accuracy in the z-direction. Similarly, piezoelectric positioners are used to control movement in the $\mathrm{x}-\mathrm{y}$ plane as well, with a maximum scan range typically around $100 \times$ 100 microns. 


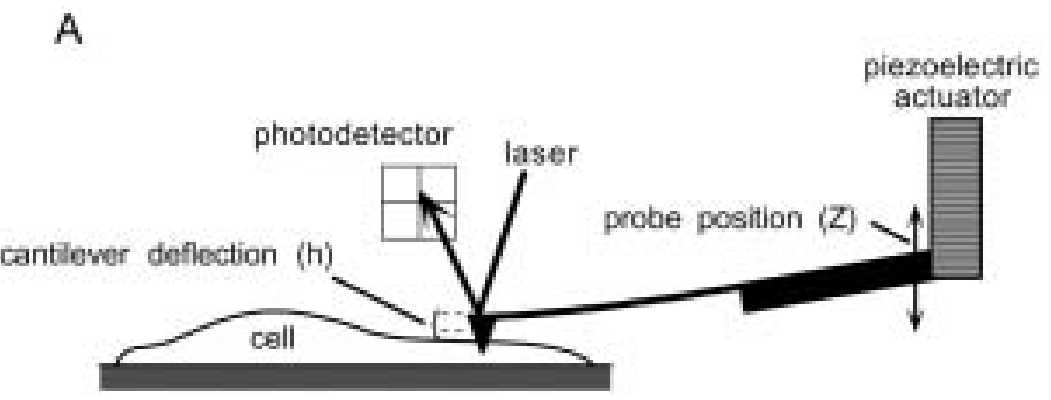

B

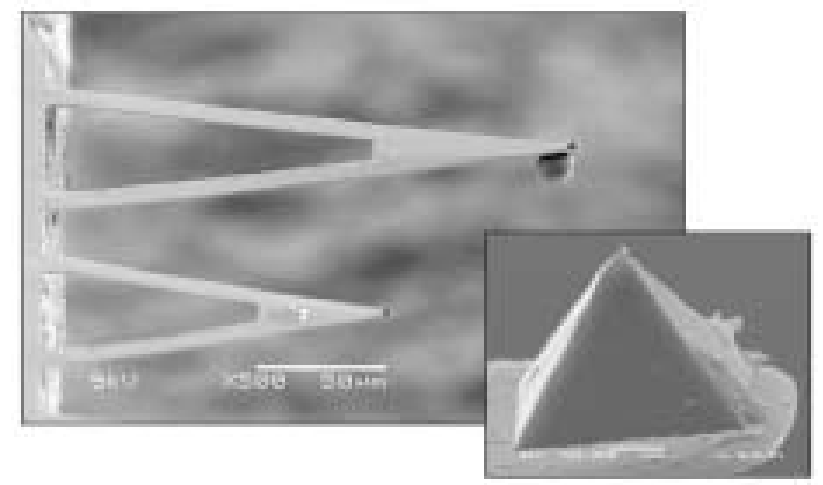

Fig. 2. (A) Schematic of the atomic force microscope (AFM). Deflection of the AFM cantilever probe is sensed from the reflection of a laser onto a four-quadrant photodetector, and the position of the probe is controlled by a piezoelectric ceramic actuator. (B) SEM images of V-shaped silicon-nitride AFM probes with integrated pyramidal tips (microlevers, Veeco Metrology). One probe has a $15 \mu \mathrm{m}$ diameter polystyrene sphere attached for comparison. Inset shows detail of a pyramidal tip with some visible debris accumulated during prior scanning of cultured cells. Scale bars are $50 \mu \mathrm{m}$ and $1 \mu \mathrm{m}$, respectively.

In the standard AFM configuration, the sample is positioned relative to a stationary probe. However, for cell biology applications, it is more convenient to place the entire AFM on the stage of an inverted light microscope to allow simultaneous visualization, including fluorescence microscopy, of the cells [70]. In this configuration, the AFM probe is moved relative to a stationary sample. In addition, whereas the typical setup conceals the petri dish underneath the AFM head, at least one model (the Bioscope from Digital Instruments, Santa Barbara, CA) supports the AFM head from behind. This leaves the sample easily accessible for direct visual inspection and also facilitates the use of other devices such as fluid exchange systems, micromanipulators, and the like that enhance its versatility for cell biology applications.

\subsection{The AFM experiment}

There are two primary forms of AFM imaging in which the probe is raster scanned over the sample. Tap- ping mode imaging involves oscillating the probe near its resonance frequency and using feedback to maintain the amplitude of the oscillation as the probe encounters different features of the sample. Contact-mode imaging involves simply raster scanning the tip over the sample using feedback to maintain a constant deflection (force) of the cantilever (Fig. 3). In both cases, a topographical image of the sample is constructed from the $\mathrm{z}$-position of the probe at each $\mathrm{x}-\mathrm{y}$ pixel location. Tapping mode has the advantage of intermittent contact with the sample, virtually eliminating any frictional forces and thus minimizing distortion or damage to the cell [72]. Tapping-mode based elastography techniques such as phase imaging [73,74] and force modulation [75-77] yield images with contrast related to local sample stiffness but have not been capable of yielding quantitative estimates of the elastic modulus due to complications with the analysis. Contact mode also has been shown to yield high-resolution images with cell viability sustained for several hours [66]. In addition, contact mode is easier to use than tapping mode and 


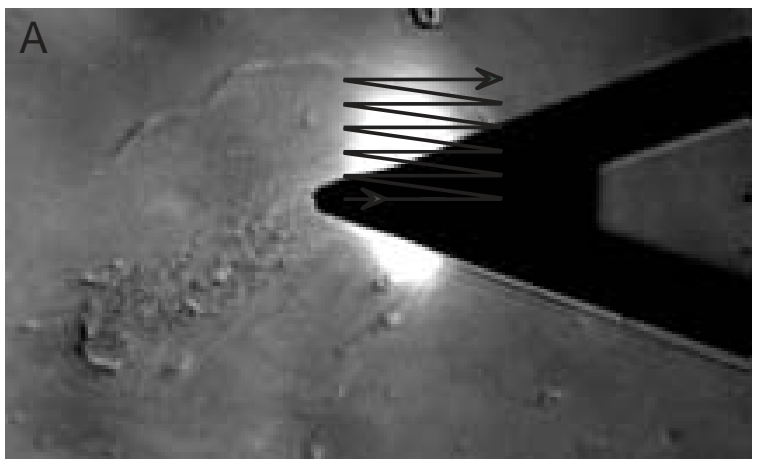

B

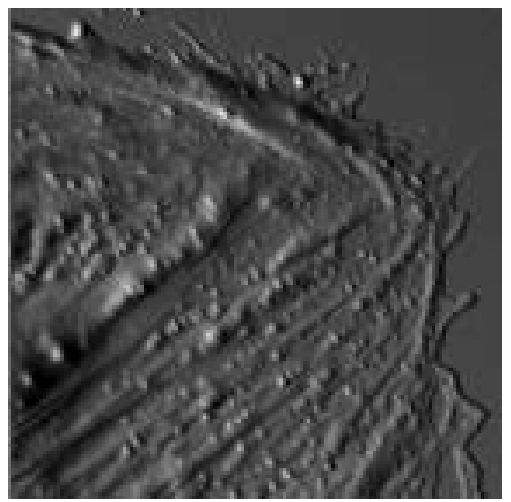

Fig. 3. (A) Inverted microscope image $(200 \times)$ of human aortic endothelial cell showing AFM probe and laser reflection, with zig-zag line indicating approximate region raster-scanned by probe. (B) Contact mode AFM image of $35 \times 35 \mu \mathrm{m}$ region of cell periphery indicated in (A).

more conducive to switching back and forth between imaging and "force mode," in which nano-indentation is used to obtain quantitative stiffness measurements.

For the AFM indentation experiment, the probe is located at a desired position over the sample and is put through an extension-retraction cycle covering a typical z-range of 1 to 3 microns at a typical frequency of 1 to $10 \mathrm{~Hz}$ (Fig. 4). As the AFM probe approaches and contacts the sample at position $Z_{o}$, further extension of the probe $\left(Z-Z_{o}\right)$ is converted into a combination of probe deflection, $h$, and sample indentation, $D=$ $\left(Z-Z_{o}\right)-h$. The indentation response depends on the spring constant of the probe, the geometry of the tip, and the mechanical properties of the sample. One also can vary the rate of indentation to study viscoelastic properties. Thus, by monitoring the z-position and deflection of the probe (the so-called "force curve"), one can obtain an indentation curve of indentation force versus depth that can be analyzed to extract the elastic material properties of the sample, as discussed below.

Force mapping is a hybrid combination of imaging and force probing that involves making a series of in-
A

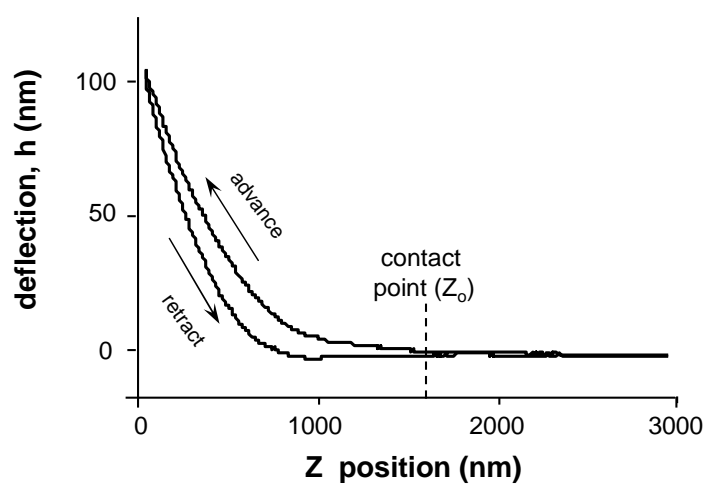

B

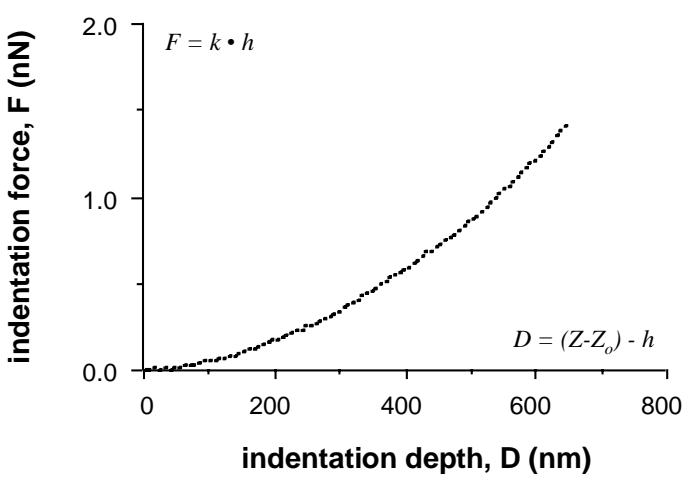

Fig. 4. The AFM cell indentation experiment. (A) Measurements of cantilever deflection versus Z-position during advancement and retraction of the probe yield the so-called "force curve" that includes information about the viscoelastic properties of the cell. Once the contact point is identified, the raw force curve is converted to a plot of indentation force versus depth (B), which is analyzed to determine cell mechanical properties (see text for details).

dentations in an array covering a region of interest on the sample and reconstructing an isoforce image from the z-position at which the probe reaches a preset constant deflection (i.e., contact force) [78]. In such images, larger $\mathrm{z}$-values are interpreted as softer regions of the sample because a greater motion of the probe would have been required to achieve the preset force. However, in samples such as living cells, such images are complicated by the highly variable topography of the cell, which also influences the z-position at which a given contact force is achieved. Therefore, it is more accurate to analyze the indentation data and create an image that directly represents the elastic properties obtained at each pixel location. This is the method of AFM elastography.

Of course, the second half of the indentation cycle (i.e., the retraction curve) also contains useful information. Differences between the indentation and retraction curves reflect viscoelastic hysteresis of the sample. Upon retraction of the probe, the AFM tip may 
adhere to the sample and cause negative deflections of the probe. Such retraction events are the focus of experiments on protein unfolding [79], receptor-ligand binding [80], and cell-cell adhesion [81].

With such a range of capabilities, the AFM has proven to be a very versatile tool for applications in cell biology (an extensive review of the state-of-theart can be found in reference [82]), and many of the properties that can be measured with AFM may depend on whether the cell is normal or abnormal. Herein, attention is focused on use of the AFM for mapping cell mechanical properties as an indicator of disease. Although the AFM has yet to achieve its full potential as a tool for measuring the micromechanical properties of cells, there is still much information to be garnered from the standard cell indentation test. As the field of cell elastography advances, other experimental protocols and methods of analysis may be developed, but the classic AFM indentation experiment is likely to remain an important component of any battery of cell mechanical tests.

\subsection{Analysis and visualization of AFM indentation data}

Since the earliest AFM studies of soft biological samples [83,84], the prevalent method of analyzing AFM indentation data has been application of the so-called "Hertz model" of contact between two elastic bodies. Actually, it was Love who first obtained the widely used solution for indentation with a cone [85]. However, Hertz originally had solved the contact problem for the sphere and other smooth ellipsoidal geometries [86], so herein we refer to this general class of indentation problems as the "Hertz theory." In particular, the equations relating force and depth for indentation with a cone and a sphere, respectively, are given by:

$$
\begin{aligned}
& F=\frac{2}{\pi} \frac{E}{\left(1-v^{2}\right)} \tan (\alpha) D^{2} \text { and } \\
& F=\frac{4}{3} \frac{E}{\left(1-v^{2}\right)} \sqrt{R D^{3}}
\end{aligned}
$$

where $\alpha$ is the semi-included angle of the cone tip, $R$ is the sphere radius, and $\nu$ is the Poisson's ratio that determines the amount of lateral expansion that accompanies axial compression (note that $\nu=0.5$ for water and other incompressible materials, and this value often is assumed for cells). It is important to appreciate that these solutions are based upon a number of simplifying assumptions, including homogeneous, isotropic, linear elastic material properties; axisymmetry; infinitesi- mal deformations; infinite sample thickness and dimensions; and a smooth sample surface. Therefore, caution must be exercised when such theoretical solutions are applied to the more complex AFM-cell indentation problem.

Analysis based on the Hertz theory has been tested on thin films of gelatin, polyacrylamide, and similar substances $[71,74,84]$, and a strong correlation (even numerical equality) between the microscopic and macroscopic elastic properties has been demonstrated in some cases $[87,88]$. However, because these test materials actually satisfy several key assumptions of the theory (e.g., thick films with homogeneous, isotropic, linear elastic material properties), this agreement does not ensure that the analysis also will be accurate or appropriate for more complex materials such as cells. In particular, whereas the classical analysis assumes that the sample is well characterized by a single Young's modulus, like a piece of rubber or steel, several recent studies suggest that nonlinear material properties may be important at the cellular level $[25,71,89,90]$. In addition, the classical analysis assumes infinitesimal sample deformation, whereas for soft samples such as cells indented with the standard pyramidal tip, local deformations near the probe always fall into the finite strain regime [91,92], even for small indentations relative to the sample thickness. Interestingly, our recent finite element model studies of AFM indentation suggest that, if the sample is indeed a linear elastic material, then the Hertz theory may yield accurate estimates of the material properties even when applied to finite indentations [91]. However, the linear elastic condition must be demonstrated experimentally and not assumed a priori. Fidelity of the calculated elastic properties also requires accurate identification of the contact point [88], accurate calibration of the probe spring constant [93], and accurate representation of the detailed tip geometry [90,91], each of which can be challenging in practice.

To address some of the practical and theoretical limitations of the Hertz theory, alternative approaches for analyzing AFM indentation data have been developed. For example, rather than fitting the entire post-contact data set, Radmacher and coworkers applied the Hertz equation using two post-contact data points to solve for the two unknowns: Young's modulus and contact point [94]. When applied to cells, this method showed that the Young's modulus often depends on the depth range from which the two data points are selected, with the value of $E$ increasing as the points are chosen from deeper indentations [94]. However, data from 
deeper regions often yielded an inaccurate estimate of the contact point; thus, the resulting modulus values also were questionable. Hoh's technique of force integration to equal limits, or FIEL mapping, overcomes some practical difficulties with the standard analysis of AFM data such as contact point uncertainty, to yield regional maps of relative cell stiffness from the area under the force curve [59]. However, this analysis ultimately is founded on the same assumptions as the Hertz model and therefore is subject to the same theoretical limitations. McElfresh and coworkers developed an analysis that explicitly accounts for surface interactions with the cell membrane for AFM indentation of sperm cells, but the approach makes other assumptions, such as single-point contact, that limit applicability to more general cell types [89]. One of the more sophisticated approaches to date is by Mahaffy et al. [71], in which small perturbations upon a large indentation were used to extract frequency-dependent elastic and viscous moduli of polyacrylamide films. When applied to fibroblasts, the method revealed an elastic modulus that increased substantially with indentation depth, possibly indicative of nonlinear elastic cell material properties. However, the potential influence of the underlying rigid substrate was not taken into account specifically. Recently, Demitriadis and coworkers developed an empirical correction for the effects of finite sample thickness on the AFM indentation response [88]. This correction yielded consistent Young's moduli for thin $(<5 \mu \mathrm{m})$ and thick poly (vinyl alcohol) films, although validation of the method on more complex samples and living cells awaits further study.

We recently published a new analysis method whereby computation of an apparent elastic modulus as a function of indentation depth can reveal nonlinearity and heterogeneity of material properties from standard AFM indentation tests [91]. The concept is similar to that of Radmacher et al., mentioned above [94], but in our implementation the contact point is determined independently of the modulus and remains constant for all indentation depths, yielding elastic properties that more properly reflect the material properties of the sample. The form of the governing equation is derived from the Hertz theory:

$$
F=2 \pi \tilde{E} \phi(D),
$$

where $\tilde{E}$ is a generalized elastic modulus (equivalent to $E / 2\left(1-\nu^{2}\right)$ for linear elastic materials, but also may be defined in terms of nonlinear elastic material constants [91]), and $\phi(D)$ is a function of the indenter geometry that determines the depth dependence of the indentation response. Since $F$ and $D$ are measured in the AFM experiment (Fig. 4b), and $\phi(D)$ is determined by the tip geometry, the above equation may be solved at each force-depth datum to obtain a "point-wise" apparent modulus [91].

Extensive finite element model validation illustrated how depth dependence of the point-wise modulus is sensitive to a number of factors likely to be important for cell indentation, including nonlinear mechanical properties and through-thickness material heterogeneity. The point-wise analysis has been used to distinguish different cell types [90] and also is readily applied to force curves with abrupt features as may occur when probing organelles [95]. Unfortunately, some characteristics of the shape of the curve are not unique - for example, some forms of material heterogeneity look similar to material nonlinearity. Therefore, a more sophisticated battery of tests is required to make such distinctions. Nevertheless, AFM indentation tests clearly have potential to yield more information about cell mechanical properties than a single modulus value, and to ignore this information is to discard potentially critical data on the detailed mechanical properties of the cell.

\section{Probing cell mechanics with AFM}

Due to the unique capabilities of AFM as an imaging tool for scanning the surface of living cells, numerous studies have been conducted comparing such images with alternative modalities. For example, while scanning electron microscopy (SEM) still can resolve greater detail on prepared cell samples [69], some AFM studies have found features of the surface of living cells not observed by SEM [66]. Importantly, AFM also can be used to monitor dynamic cellular processes, including migration and division [96], cytoskeletal reorganization [97], exocytosis [98], and even the response of cancer cells to antitumor drug treatment [99]. Confocal microscopy combined with immunolabeling and fluorescent probes such as green fluorescent protein (GFP) allows imaging the dynamics of living cells with molecular specificity but cannot achieve the spatial resolution of AFM. Therefore, combining imaging modalities with the AFM mounted directly on the stage of an inverted light microscope aids identification of cellular structures observed with AFM [22,23,100]. For example, Fig. 5 shows a human aortic endothelial cell imaged with AFM in contact mode and also with a fluorescent microscope after the cell had been fixed and stained with rhodamine-phalloidin, indicating a strong 

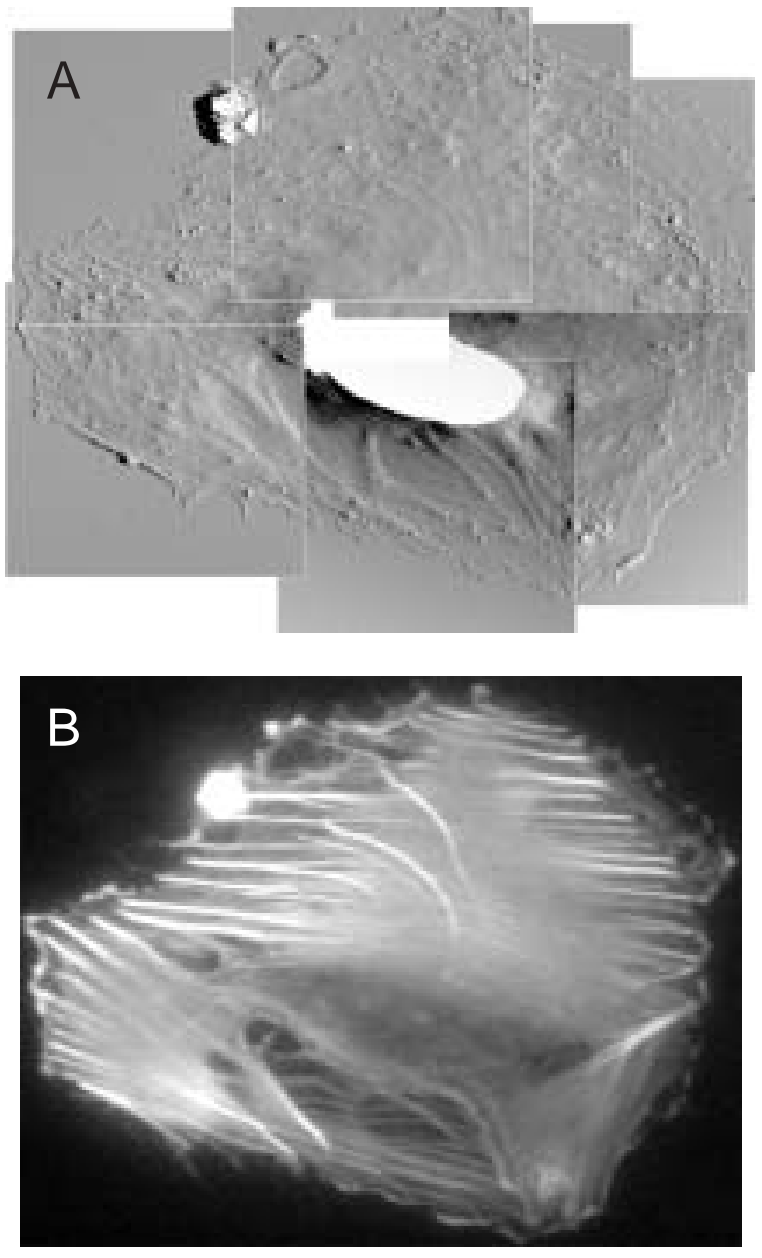

Fig. 5. Human aortic endothelial cell. (A) Topographic image constructed from a mosaic of seven individual $60 \times 60 \mu \mathrm{m}$ contact mode AFM scans. (B) Fluorescent image of same cell fixed and stained with rhodamine phalloidin to visualize cytoskeletal f-actin.

correlation between the ridge structures observed with AFM and actin stress fibers in the cell.

As emphasized above, in addition to imaging the surface topography, AFM is capable of mapping the elastic properties of living cells, which has yielded interesting insights into a number of physiologic cell processes. For example, monitoring the edge dynamics of migrating fibroblasts revealed a thin margin with uniform elastic properties more consistent with an actin- or myosin-based mechanism of extension rather than localized blebbing [94]. Endothelial cells have been observed to get less stiff in the presence of attached monocytes, which indicates a possible mechanism to facilitate monocyte migration, a key process in the inflammatory response in the later stages of atherogenesis [101]. Regional measurements of the mechanical properties of endothelial cells exposed to shear flow show that the upstream edge is earliest to respond with increased stiffening that later extends to the entire cell [102], which suggests localized control of cytoskeletal organization. AFM also has been used to monitor temporal changes in mechanical properties during cell division [103] and revealed an increase in stiffness in the equatorial region that precedes any detectable cleavage furrow by more than two minutes [104].

The AFM has been used to measure characteristic differences in both the elastic and viscous properties of various cell types [69,90,105]. Differences in stiffness also have been observed between the nucleus and cytoplasm of the same cell [59,66,74,102,106,107], and in some cases regions of altered stiffness have been identified by AFM that do not seem to have an obvious anatomical correlate [59]. Substrate-dependent differences in cell elastic properties have been reported as well [108].

To elucidate how cell mechanical properties are related to the structure and function of the underlying cytoskeleton, a number of studies have examined the effects of chemical treatments or genetic mutations that target specific cytoskeletal constituents. In general, the actin cytoskeleton has a dominant effect on cell stiffness measured with AFM [22,23,97,109,110]. Correlation of regional cell mechanics with underlying cytoskeletal components by combining AFM and fluorescent microscopy with immunolabeling showed that actin and intermediate filaments make a major contribution to elastic properties, whereas microtubules make a negligible contribution to cell elastic properties [22,23]. In another study, actin depolymerization by cytochalasin-D decreased elastic and viscous properties of L929 fibroblasts, whereas microtubule depolymerization by nocodazole or colcemid increased elastic stiffness without altering viscous properties [110]. The membrane-associated cytoskeletal binding protein vinculin also was found to play an important functional role in stabilizing focal adhesions such that vinculindeficient mouse embryonic F9 carcinoma cells showed a markedly decreased stiffness compared to wild-type cells [111]. Clearly, cell mechanics is an important indicator of cytoskeletal structure and function [112].

In particular, actin stress fibers are prominent linear structures comprised of actin and myosin [113] that provide a contractile apparatus in many cultured nonmuscle cell types, as well as in vascular endothelial cells in some physiologic conditions [32,114]. AFM force mapping studies show that these structures are very stiff compared to any other cellular component [23]. We 
have found that, in cultured human aortic endothelial cells, stress fibers were not only stiffer than the surrounding cytoplasm, but the point-wise modulus on the stress fiber increased with indentation depth to maximum values that were large $(12-24 \mathrm{kPa})$ compared with the more uniform values on the surrounding cytoplasm (1-5 kPa) (Fig. 6). When the same region of the cell was examined after 45 minutes' treatment with $4 \mu \mathrm{M}$ cytochalasin-B, no stress fibers were visible in the AFM image (not shown) and the cell behaved uniformly like a soft, homogeneous material with a constant stiffness $(0.5-1.5 \mathrm{kPa})$. Previous studies have indicated that the cytoskeleton may exhibit strain hardening, with stiffness increasing as deformation increases [25]. Even with linear elastic cytoskeletal elements, such nonlinearity may arise from purely structural considerations, depending on how the elements are interconnected [26]. Our data suggest the cytoskeletal elements themselves may be inherently nonlinear elastic, which is an important distinction for accurately characterizing cellular stresses and for properly identifying the biomechanical fingerprint of the cell.

Although the vast majority of AFM elastography studies to date have focused on characterizing normal cells and cell behavior, a few key AFM studies have begun to examine how cell mechanical properties may be altered by disease processes. In particular, a comparison of normal and SV40-transformed human dermal fibroblasts found comparable membrane cortical tension, but the apparent viscosity was $30 \%$ lower for the transformed cells, which suggests that such measurements may offer new markers of oncogenic transformation [115]. More recently, Lekka and coworkers have shown that cancerous human bladder epithelial cells have a Young's modulus about one-tenth that of corresponding normal cells [10]. Remarkably, the abnormal modulus values returned toward normal when the cancerous cells were treated with microcrystalline chitosan [116], a drug shown to inhibit glycolytic activity in tumor cells. Such studies may provide critical data for evaluating and understanding candidate therapeutic strategies using single cell analysis, possibly even on a patient-specific basis following biopsy. Taken together with the growing data relating cell mechanical properties to cytoskeletal structure and substrate adhesion, these studies underscore the tremendous potential for AFM elastography of living cells to provide novel biomechanical markers that will enhance the detection, diagnosis, and treatment of disease.

\section{Current limitations and future directions for AFM elastography}

For all of its advantages, the AFM still has a number of limitations that must be overcome to realize the full potential of this unique tool. For instance, accuracy of the cantilever spring constant traditionally has been one limitation of using the AFM for quantitative measurements of mechanical properties. In particular, variations in the thickness [117] and stoichiometry [118] of commercially available AFM cantilevers can result in spring-constant variability of nearly an order of magnitude between batch-produced wafers [61]. This necessitates individual calibration for applications (such as elastography) in which accuracy of the contact force is critical. Fortunately, several methods now exist for nondestructively calibrating AFM cantilevers [61-63], and it has been shown that, for a given wafer, springconstant variability of individual cantilevers is within about $10 \%$ of the average value for that wafer [93].

Identification of the exact point of contact between the AFM tip and the sample is another source of error in estimating mechanical properties from indentation tests. On stiff samples, the contact point is detected readily as a discontinuity in the slope (first derivative) or a spike in the curvature (second derivative) of the raw force curve [58]. However, this often is ineffective when applied to indentations on soft samples because the transition from pre-contact to post-contact is smooth and obscured by noise in the data. When indenting cells with a pyramidal tip, the problem is exacerbated by the fact that initial contact forces are minimal as the smallest part of the probe tip first contacts the soft cell membrane. Rather than relying on visual inspection of the force curve [88], the contact point may be estimated by including it as an unknown variable when analyzing post-contact data [94], though this is prone to errors with deeper indentations as mentioned above. Alterations in the thermal noise spectrum of the cantilever as it approaches the surface also may reveal contact if the long-range interaction forces are well characterized [119]. Alternative probe-tip geometries or instrumented probes that utilize MEMS technology [120] may allow improved identification of initial cell contact. Another approach is to develop methods of analysis that are insensitive to the precise point of contact, such as FIEL mapping [59]. Ultimately, some independent method for verifying the contact point needs to be developed.

Most analysis methods focus on estimating cellular elastic properties and neglect viscoelastic behav- 


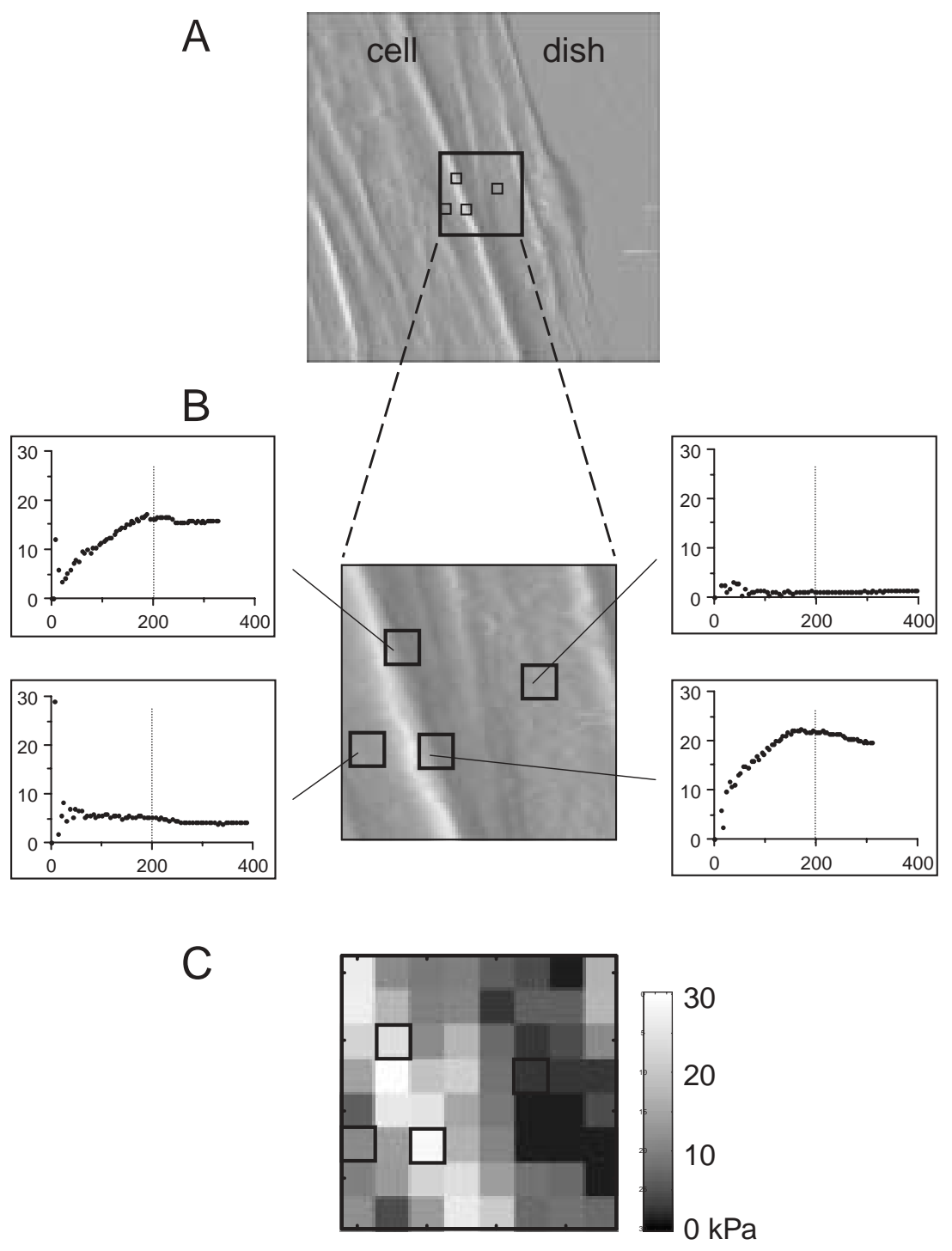

Fig. 6. (A) Contact mode AFM image $(15 \times 15 \mu \mathrm{m})$ of stable edge of human aortic endothelial cell on a tissue culture dish at room temperature. (B) Magnified $3.5 \times 3.5 \mu \mathrm{m}$ square region of panel A where an $8 \times 8$ array of 64 indentations was performed to measure local cell mechanical properties. Curves indicate pointwise modulus $(0-30 \mathrm{kPa})$ versus indentation depth $(0-400 \mathrm{~nm})$ at selected locations on and off a prominent stress fiber. (C) Corresponding $8 \times 8$ pixel grayscale map of pointwise modulus at an indentation depth of $200 \mathrm{~nm}$. Black squares indicate locations highlighted in panel $\mathrm{B}$.

ior. This may be significant particularly since, in some cases, diseased cells may have the same elastic properties as do normal cells but may have altered viscous properties [11,115,121]. In addition to the indentation experiments that have become standard with AFM, it is necessary to develop more sophisticated tests (e.g., creep and relaxation [59,110], frequencydependent microrheology [71]), possibly combining indentation with other modes of cell deformation (e.g., in-plane stretch [91]), to more completely characterize cell mechanical properties. AFM has the flexibility to perform such tests but has yet to be fully developed for this purpose.

It also is necessary to validate whether micro-scale mechanical properties can be interpreted in the same context as are macro-scale mechanical properties; i.e., to test whether the continuum assumption is valid in the AFM indentation experiment. In particular, Stamenovic and Coughlin recently pointed out that alternative methods for measuring cell mechanical proper- 
ties (cell poking, micropipette aspiration, and magnetometry) consistently yield Young's moduli of different orders of magnitude [122]. There is an apparent correlation with the length scale over which the cell is interrogated that is consistent with a discrete structural model of the cytoskeleton [122]. On the other hand, these alternative measurement techniques actually may measure different aspects of cell mechanical properties. In fact, a recent study on elastomeric polymer gels showed that, when properly corrected for tip geometry, the Young's modulus determined by AFM using spherical-tipped cantilevers closely matched the results of macroscopic indentation tests [88]. For standard pyramid tips, the microscopic modulus was larger than the macroscopic modulus [88]; but the authors analyzed this data assuming an ideal cone geometry rather than a more accurate blunt cone [91], an error that is known to overestimate Young's modulus values obtained from indentation tests $[90,123]$. While these studies suggest that some porous polymeric materials behave like a continuum when probed with AFM, similar validation studies must be performed on increasingly complex materials before we can understand fully such measurements of living cells.

Another limitation of AFM elastography (and of cell mechanics measurements in general) is that typical experiments are highly time- and user-intensive, so that a limited number of cells can be analyzed in one day. Until the AFM can be used to rapidly evaluate large populations of cells, it will not realize its full potential for basic science and clinical applications, such as screening for disease or evaluating therapeutic treatments. Therefore, an essential modification to expand the use of this technology is to increase throughput. Arrays of multiple probes have been used for rapidly imaging large areas of silicon wafers for the semiconductor industry [124-126], though such technology has not been tested yet in cell biology applications. One major challenge is to position automatically such irregular biological samples under the probe tip for consistent and rapid sequential testing.

As AFM elastography evolves, the mechanical tests become increasingly sophisticated, and data sets become increasingly large and complex, computational methods and imaging techniques will play a critical role in the analysis and visualization of cell mechanics data. Already, we have identified many limitations when applying the standard Hertz theory, and preliminary finite element models have motivated novel experiments and yielded alternative methods of analysis that promise to increase the information that can be obtained from AFM indentation tests [91]. Finite element models also can accommodate challenging aspects of the AFM indentation problem such as nonaxisymmetry of the tip geometry, inclination angle of the cantilever relative to the cell surface, the irregular topography of the cell, and the more complex cell mechanical properties, including nonlinearity, viscoelasticity, anisotropy, heterogeneity, and even multi-phasic material composition. Such computational methods also will be critical in evaluating alternative theoretical models of the cell, including discrete structurally based models of the cytoskeleton [127]. Recently, the sophistication of such models has increased [92,128], but the AFM indentation problem has yet to be fully characterized. Such detailed computational models also can be used for simulation purposes to better understand how forces at the cantilever tip are manifest as the raw force curve data, as instructional tools to expose a wider population to the AFM, and, ultimately, perhaps as inverse models for extracting cell mechanical properties from individual cell mechanics experiments. Computers also will play an important role in the visualization of increasingly complex elastography data using novel image-processing methods [129].

\section{Summary and perspective}

In the past decade, the AFM rapidly has become one of the most widely used and versatile tools for studying and physically interacting with living cells. In particular, AFM elastography, which capitalizes on the unique capability of combining mechanical measurements and topological imaging, holds great promise in the field of cell biology. A growing body of data relating cell mechanical properties to cytoskeletal structure and substrate adhesion suggests that single-cell elastography may provide sensitive indicators of the presence of disease. However, it will serve us well to heed the words of Werner Heisenberg who cautioned, “... We have to remember that what we observe is not nature in itself but nature exposed to our method of questioning" [130]. A number of technical and practical hurdles remain in the way of obtaining accurate and meaningful cell mechanics measurements with sufficient throughput that they will be practical for reliably examining large populations of cells. Nevertheless, as one powerful method of questioning, the future holds tremendous potential for AFM elastography of living cells to provide novel biomechanical markers that will enhance the detection, diagnosis, and treatment of disease. 


\section{Acknowledgements}

The author wishes to thank Dr. Frank Yin at Washington University for first introducing him to the AFM and Dr. Jan Hoh at Johns Hopkins University for generously sharing his insight and imagination. Funding from NSF CAREER award BES-0239138 (KDC) also is gratefully acknowledged.

\section{References}

[1] T. Lyyra, I. Kiviranta, U. Väätäinen, H.J. Helminen and J.S Jurvelin, In vivo characterization of indentation stiffness of articular cartilage in the normal human knee, Biomed Mat Res 48 (1999), 482-487.

[2] Y. Lanir, S. Dikstein, A. Hartzshtark and V. Manny, In-vivo indentation of human skin, J Biomech Eng 112 (1990), 6369.

[3] Y. Zheng, A.F. Mak and B. Lue, Objective assessment of limb tissue elasticity: development of a manual indentation procedure, J Rehabil Res Dev 36 (1999), 71-85.

[4] R.C. Appleyard, M.V. Swain, S. Khanna and G.A. Murrell, The accuracy and reliability of a novel handheld dynamic indentation probe for analysing articular cartilage, Phys Med Biol 46 (2001), 541-550.

[5] J. Ophir, S.K. Alam, B. Garra, F. Kallel, E. Konofagou, T. Krouskop and T. Varghese, Elastography: ultrasonic estimation and imaging of the elastic properties of tissues, Proc Instn Mech Engrs 213 (1999), 203-233.

[6] A. Manduca, T.E. Oliphant, M.A. Dresner, J.L. Mahowald, S.A. Kruse, E. Amromin, J.P. Felmlee, J.F. Greenleaf and R.L. Ehman, Magnetic resonance elastography: non-invasive mapping of tissue elasticity, Med Image Anal 5 (2001), 237254.

[7] E.E. Konofagou, J.D. D'hooge and J. Ophir, Myocardial elastography-a feasibility study in vivo, Ultrasound in Med and Biol 28 (2002), 475-482.

[8] T. Varghese, J.A. Zagzebski, P. Rahko and C.S. Breburda, Ultrasonic imaging of myocardial strain using cardiac elastography, Ultrason Imaging 25 (2003), 1-16.

[9] C.L. de Korte, M.J. Sierevogel, F. Mastik, C. Strijder, J.A. Schaar, E. Velema, G. Pasterkamp, P.W. Serruys and A.F.W. van der Steen, Identification of atherosclerotic plaque components with intravascular ultrasound elastography in vivo: a Yucatan pig study, Circulation 105 (2002), 1627-1630.

[10] M. Lekka, P. Laidler, D. Gil, J. Lekki, Z. Stachura and A.Z. Hrynkiewicz, Elasticity of normal and cancerous human bladder cells studied by scanning force microscopy, Eur Biophys J 28 (1999), 312-316.

[11] W.R. Jones, H.P. Ting-Beall, G.M. Lee, S.S. Kelley, R.M. Hochmuth and F. Guilak, Alterations in the Young's modulus and volumetric properties of chondrocytes isolated from normal and osteoarthritic human cartilage, J Biomech 32 (1999), 119-127.

[12] M.R. Zile, K. Richardson, M.K. Cowles, J.M. Buckley, M. Koide, B.A. Cowles, V. Gharpuray and G. Cooper IV, Constitutive properties of adult mammalian cardiac muscle cells, Circulation 98 (1998), 567-579.

[13] M.M. Brandão, A. Fontes, M.L. Barjas-Castro, L.C. Barbosa, F.F. Costa, C.L. Cesar and S.T.O. Saad, Optical tweezers for measuring red blood cell elasticity: application to the study of drug response in sickle cell disease, Eur J Hematol 70 (2003), 207-211.

[14] J. Eberwine, H. Yeh, K. Miyashiro, Y. Cao, S. Nair, R. Finnell, M. Zettel and P. Coleman, Analysis of gene expression in single live neurons, Proc Natl Acad Sci USA 89 (1992), 3010-3014.

[15] R. Todd and D.H. Margolin, Challenges of single-cell diagnostics: analysis of gene expression, Trends Mol Med $\mathbf{8}$ (2002), 254-257.

[16] Y.C. Fung, Biomechanics: Mechanical Properties of Living Tissues, 2nd ed. New York: Springer-Verlag, 1993.

[17] A.F. Mak, W.M. Lai and V.C. Mow, Biphasic indentation of articular cartilage - 1: Theoretical analysis, J Biomech 20 (1987), 703-714.

[18] W.M. Lai, J.S. Hou and V.C. Mow, A triphasic theory for the swelling and deformation behaviors of articular cartilage, $J$ Biomech Eng 113 (1991), 245-258.

[19] U. Bagge, R. Skalak and R. Attefors, Granulocyte rheology, Adv Microcirc 7 (1977), 29.

[20] E. Evans and A. Yeung, Apparent viscosity and cortical tension of blood granulocytes determined by micropipet aspiration, Biophys J 56 (1989), 151-160.

[21] N. Wang, Mechanical interactions among cytoskeletal filaments, Hypertension 32 (1998), 162-165.

[22] H. Haga, S. Sasaki, K. Kawabata, E. Ito, T. Ushiki and T. Sambongi, Elasticity mapping of living fibroblasts by AFM and immunofluorescence observation of the cytoskeleton, Ultramicroscopy 82 (2000), 253-258.

[23] C. Rotsch and M. Radmacher, Drug-induced changes of cytoskeletal structure and mechanics in fibroblasts: an atomic force microscopy study, Biophys $J \mathbf{7 8}$ (2000), 520-535.

[24] D.E. Ingber, S.R. Heidemann, P. Lamoureux and R.E. Buxbaum, Opposing views on tensegrity as a structural framework for understanding cell mechanics, J Appl Physiol 89 (2000), 1663-1678.

[25] J. Pourati, A. Maniotis, D. Spiegel, J.L. Schaffer, J.P. Butler, J.J. Fredberg, D.E. Ingber, D. Stamenovic and N. Wang, Is cytoskeletal tension a major determinant of cell deformability in adherent endothelial cells? Am J Physiol 247 (1998), C1283-C1289.

[26] D. Stamenovic, J. Fredberg, N. Wang, J. Butler and D. Ingber, A microstructural approach to cytoskeletal mechanics based on tensegrity, J Theor Biol 181 (1996), 125-136.

[27] N.O. Petersen, W.B. McConnaughey and E.L. Elson, Dependence of locally measured cellular deformability on position on the cell, temperature, and cytochalasin B, Proc Nat Acad Sci 79 (1982), 5327-5331.

[28] F. Guilak, The deformation behavior and viscoelastic properties of chondrocytes in articular cartilage, Biorheology 37 (2000), 27-44.

[29] A.J. Maniotis, C.S. Chen and D.E. Ingber, Demonstration of mechanical connections between integrins, cytoskeletal filaments, and nucleoplasm that stabilize nuclear structure, Proc Natl Acad Sci USA 94 (1997), 849-854.

[30] S.R. Heidemann, S. Kaech, R.E. Buxbaum and A. Matus, Direct observations of the mechanical behaviors of the cytoskeleton in living fibroblasts, J Cell Biol 145 (1999), 109122.

[31] K.D. Costa, W.J. Hucker and F.C.P. Yin, Buckling of actin stress fibers: a new wrinkle in the cytoskeletal tapestry, Cell Motil Cytoskeleton 52 (2002), 266-274.

[32] P. Sipkema, P.J.W. van der Linden, N. Westerhof and F.C.P. Yin, Effect of cyclic axial stretch of rat arteries on endothelial 
cytoskeletal morphology and vascular reactivity, $J$ Biomech 36 (2003), 653-659.

[33] N. Akkas, ed., Biomechanics of Active Movement and Division of Cells, NATO ASI Series 84 (1994), New York: Springer-Verlag.

[34] V.C. Mow, F. Guilak, R. Tran-Son-Tay and R.M. Hochmuth, eds, Cell Mechanics and Cellular Engineering (1994), New York: Springer-Verlag.

[35] D. Boal, Mechanics of the Cell, (2002), New York: Cambridge University Press.

[36] C. Pasternak, S. Wong and E.L. Elson, Mechanical function of dystrophin in muscle cells, J Cell Biol 128 (1995), 355361.

[37] J.D. Porter, A.P. Merriam, S. Khanna, F.H. Andrade, C.R. Richmonds, P. Leahy, G. Cheng, P. Karathanasis, X. Zhou, L.L. Kusner, M.E. Adams, M. Willem, U. Mayer and H.J. Kaminski, Constitutive properties, not molecular adaptations, mediate extraocular muscle sparing in dystrophic $\mathrm{mdx}$ mice, FASEB J 17 (2003), 893-895.

[38] D.M. Salter, S.J. Millward-Sadler, G. Nuki and M.O. Wright, Differential responses of chondrocytes from normal and osteoarthritic human articular cartilage to mechanical stimulation, Biorheology 39 (2002), 94-108.

[39] Z.-Z. Wu, G. Zhang, M. Long, H.-B. Wang, G.-B. Song and S.-X. Cai, Comparison of the viscoelastic properties of normal hepatocytes and hepatocellular carcinoma cells under cytoskeletal perturbation, Biorheology 37 (2000), 279-290.

[40] G.B. Nash, C.S. Johnson and H.J. Meiselman, Mechanical properties of oxygenated red blood cells in sickle cell (HbSS) disease, Blood 63 (1984), 73-82.

[41] S.K. Ballas, G.J. Dover and S. Charache, Effect of hydroxyurea on the rheological properties of sickle erythrocytes in vivo, Am J Hematol 32 (1989), 104-111.

[42] J.L. Wautier, G.W. Schmid-Schonbein and G.B. Nash, Measurement of leukocyte rheology in vascular disease: clinical rationale and methodology: International society of clinical hemorheology, Clin Hemorheol Microcirc 21 (1999), 7-24.

[43] J.G.G. Dobbe, M.R. Hardeman, G.J. Streekstra, J. Strackee, C. Ince and C.A. Grimbergen, Analyzing red blood celldeformability distributions, Blood Cells Mol Dis 28 (2002), 373-384.

[44] R.M. Hochmuth and R.E. Waugh, Erythrocyte membrane elasticity and viscosity, Annu Rev Physiol 49 (1987), 209219.

[45] G.W. Schmid-Schonbein, K.-L.P. Sung, H. Tozeren, R. Skalak and S. Chien, Passive mechanical properties of human leukocytes, Biophys J 36 (1981), 243-256.

[46] M. Sato, M.J. Levesque and R.M. Nerem, Micropipette aspiration of cultured bovine aortic endothelial cells exposed to shear stress, Arteriosclerosis 7 (1987), 276-286.

[47] H. Miyazaki, Y. Hasegawa and K. Hayashi, A newly designed tensile tester for cells and its application to fibroblasts, $J$ Biomech 33 (2000), 97-104.

[48] J.D. Humphrey, H.R. Halperin and F.C.P. Yin, Small indentation superimposed on a finite equibiaxial stretch: Implications for cardiac mechanics, J Appl Mech 58 (1991), 11081111.

[49] V.C. Mow, M.C. Gibbs, W.M. Lai, W.B. Zhu and K.A. Athanasiou, Biphasic indentation of articular cartilage-II: a numerical algorithm and an experimental study, J Biomech 22 (1989), 853-861.

[50] S. Felder and E.L. Elson, Mechanics of fibroblast locomotion: quantitative analysis of forces and motion at the leading lamellas of fibroblasts, J Cell Biol 111 (1990), 2513-2526.
[51] C. Pasternak and E.L. Elson, Lymphocyte mechanical response triggered by cross-linking surface receptors, J Cell Biol 100 (1985), 860-872.

[52] A.R. Karduna, H.R. Halperin and F.C.P. Yin, Experimental and numerical analyses of indentation in finite-sized isotropic and anisotropic rubber-like materials, Ann Biomed Eng 25 (1997), 1009-1016.

[53] N. Wang, J.P. Butler and D.E. Ingber, Mechanotransduction across the cell surface and through the cytoskeleton, Science 260 (1993), 1124-1127.

[54] S. Yamada, D. Wirtz and S.C. Kuo, Mechanics of living cells measured by laser tracking microrheology, Biophys $J$ 78 (2000), 1736-1747.

[55] F.J. Alenghat, B. Fabry, K.Y. Tsai, W.H. Goldmann and D.E. Ingber, Analysis of cell mechanics in single vinculindeficient cells using a magnetic tweezer, Biochem Biophys Res Commun 277 (2000), 93-99.

[56] J. Guck, R. Ananthakrishnan, H. Mahmood, T.J. Moon, C.C. Cunningham and J. Kas, The optical stretcher: a novel laser tool to micromanipulate cells, Biophys $J 81$ (2001), 767-784.

[57] G. Binnig, C.F. Quate and C. Gerber, Atomic force microscope, Phys Rev Lett 56 (1986), 930-933.

[58] M. Radmacher, Measuring the elastic properties of living cells by the atomic force microscope, Methods Cell Biol $\mathbf{6 8}$ (2002), 67-90.

[59] E. A-Hassan, W.F. Heinz, M.D. Antonik, N.P. D'Costa, S. Nagaswaran, C.-A. Schoenenberger and J.H. Hoh, Relative microelastic mapping of living cells by atomic force microscopy, Biophys J 74 (1998), 1564-1578.

[60] M. Tortonese, Cantilevers and tips for atomic force microscopy, IEEE Eng Med Biol Mag 16 (1997), 28-33.

[61] J.P. Cleveland, S. Manne, D. Bocek and P.K. Hansma, A nondestructive method for determining the spring constant of cantilevers for scanning force microscopy, Rev Sci Instrum 64 (1993), 403-405.

[62] J.E. Sader, I. Larson, P. Mulvaney and L.R. White, Method for the calibration of atomic force microscope cantilevers, Rev Sci Instrum 66 (1995), 3789-3798.

[63] H.-J. Butt and M. Jaschke, Calculation of thermal noise in atomic force microscopy, Nanotechnology 6 (1995), 1-7.

[64] H. Dai, J.H. Hafner, A.G. Rinzler, D.T. Colbert and R.E. Smalley, Nanotubes as nanoprobes in scanning probe microscopy, Nature 384 (1996), 147-150.

[65] P.G. Haydon, R. Lartius, V. Parpura and S.P. MarcheseRagona, Membrane deformation of living glial cells using atomic force microscopy, J Microsc 182 (1996), 114-120.

[66] J.H. Hoh and C.-A. Schoenenberger, Surface morphology and mechanical properties of MDCK monolayers by atomic force microscopy, J Cell Sci 107 (1994), 1105-1114.

[67] S.S. Schaus and E.R. Henderson, Cell viability and probe-cell membrane interactions of XR1 glial cells imaged by atomic force microscopy, Biophys J 73 (1997), 1205-1214.

[68] H.X. You, J.M. Lau, S. Zhang and L. Yu, Atomic force microscopy of living cells: a preliminary study of the disruptive effect of cantilever tip on cell morphology, Ultramicroscopy 82 (2000), 297-305.

[69] F. Braet, R. de Zanger, C. Seynaeve, M. Baekeland and E. Wisse, A comparative atomic force microscopy study on living skin fibroblasts and liver endothelial cells, J Electron Microsc 50 (2001), 283-290.

[70] P.P. Lehenkari, G.T. Charras, A. Nykanen and M.A. Horton, Adapting atomic force microscopy for cell biology, Ultramicroscopy 82 (2000), 289-295. 
[71] R.E. Mahaffy, C.K. Shih, F.C. MacKintosh and J. Kas, Scanning probe-based frequency-dependent microrheology of polymer gels and biological cells, Phys Rev Lett $\mathbf{8 5}$ (2000), 880-883.

[72] V. Vie, M.C. Giocondi, E. Lesniewska, E. Finot, J.P. Goudonnet and C. Le Grimellec, Tapping-mode atomic force microscopy on intact cells: optimal adjustment of tapping conditions by using the deflection signal, Ultramicroscopy $\mathbf{8 2}$ (2000), 279-288.

[73] R. Höper, T. Gesang, W. Possart, O.-D. Hennemann and S. Boseck, Imaging elastic sample properties with an atomic force microscope operating in tapping mode, Ultramicroscopy 60 (1995), 17-24.

[74] E. Nagao and J.A. Dvorak, Phase imaging by atomic force microscopy: analysis of living homoiothermic vertebrate cells, Biophys J 76 (1999), 3289-3297.

[75] M. Radmacher, R. Tillmann and H. Gaub, Imaging viscoelasticity by force modulation with the atomic force microscope, Biophys J 64 (1993), 735-742.

[76] S. Sasaki, M. Morimoto, H. Haga, K. Kawabata, E. Ito, T. Ushiki, K. Abe and T. Sambongi, Elastic properties of living fibroblasts as imaged using force modulation mode in atomic force microscopy, Arch Histol Cytol 61 (1998), 57-63.

[77] H. Haga, M. Nagayama, K. Kawabata, E. Ito, T. Ushiki and T. Sambongi, Time-lapse viscoelastic imaging of living fibroblasts using force modulation mode in AFM, $J$ Electron Microsc 49 (2000), 473-481.

[78] M. Radmacher, M. Fritz, C.M. Kacher, J.P. Cleveland and P.K. Hansma, Measuring the viscoelastic properties of human platelets with the atomic force microscope, Biophys $J \mathbf{7 0}$ (1996), 556-567.

[79] M. Reif, M. Gautel, F. Oesterhelt, J.M. Fernandez and H.E. Gaub, Reversible unfolding of individual titin immunoglobulin domains by AFM, Science 276 (1997), 1109-1112.

[80] C. Yuan, A. Chen, P. Kolb and V.T. Moy, Energy landscape of the streptavidin-biotin complexes measured by atomic force microscopy, Biochemistry 39 (2000), 10219-10223.

[81] M. Benoit, D. Gabriel, G. Gerisch and H.E. Gaub, Discrete interactions in cell adhesion measured by single-molecule force spectroscopy, Nature Cell Biol 2 (2000), 313-317.

[82] B.P. Jena and J.K.H. Hörber, eds, Atomic Force Microscopy in Cell Biology-Methods in Cell Biology 68 (2002), New York: Academic Press.

[83] A.L. Weisenhorn, M. Khorsandi, S. Kasas, V. Gotzos and H.-J. Butt, Deformation and height anomaly of soft surfaces studied with an AFM, Nanotech 4 (1993), 106-113.

[84] M. Radmacher, M. Fritz and P.K. Hansma, Imaging soft samples with the atomic force microscope: gelatin in water and propanol, Biophys J 69 (1995), 264-270.

[85] A.E.H. Love, Boussinesq's problem for a rigid cone, Quart J Math 10 (1939), 161-175.

[86] H. Hertz, Über die Berührung fester elastischer Körper (On the contact of elastic solids), J Reine Angew Mathematik 92 (1881), 156-171.

[87] T. Nitta, H. Haga, K. Kawabata, K. Abe and T. Sambongi, Comparing microscopic with macroscopic elastic properties of polymer gel, Ultramicroscopy 82 (2000), 223-226.

[88] E.K. Dimitriadis, F. Horkay, J. Maresca, B. Kachar and R.S. Chadwick, Determination of elastic moduli of thin layers of soft material using the atomic force microscope, Biophys $J$ 82 (2002), 2798-2810.

[89] M. McElfresh, E. Baesu, R. Balhorn, J. Belak, M.J. Allen and R.E. Rudd, Combining constitutive materials modeling with atomic force microscopy to understand the mechanical properties of living cells, Proc Natl Acad Sci USA 99(2) (2002), 6493-6497.

[90] A.B. Mathur, A.M. Collinsworth, W.M. Reichert, W.E. Kraus and G.A. Truskey, Endothelial, cardiac muscle and skeletal muscle exhibit different viscous and elastic properties as determined by atomic force microscopy, J Biomech 34 (2001), 1545-1553.

[91] K.D. Costa and F.C. Yin, Analysis of indentation: implications for measuring mechanical properties with atomic force microscopy, J Biomech Eng 121 (1999), 462-471.

[92] G.T. Charras and M.A. Horton, Determination of cellular strains by combined atomic force microscopy and finite element modeling, Biophys J 83 (2002), 858-879.

[93] T.J. Senden and W.A. Ducker, Experimental determination of spring constants in atomic force microscopy, Langmuir $\mathbf{1 0}$ (1994), 1003-1004.

[94] C. Rotsch, K. Jacobson and M. Radmacher, Dimensional and mechanical dynamics of active and stable edges in motile fibroblasts investigated by using atomic force microscopy, Proc Natl Acad Sci USA 96 (1999), 921-926.

[95] D. Ricci, M. Tedesco and M. Grattarola, Mechanical and morphological properties of living 3T6 cells probed via scanning force microscopy, Microsc Res Tech 36 (1997), 165171.

[96] Y.G. Kuznetsov, A.J. Malkin and A. McPherson, Atomic force microscopy studies of living cells: visualization of motility, division, aggregation, transformation, and apoptosis, J Struct Biol 120 (1997), 180-191.

[97] E. Henderson, P.G. Haydon and D.S. Sakaguchi, Actin filament dynamics in living glial cells imaged by atomic force microscopy, Science 257 (1992), 1944-1946.

[98] S.W. Schneider, K.C. Sritharin, J.P. Geibel, H. Oberleithner and B.P. Jena, Surface dynamics in living acinar cells imaged by atomic force microscopy: identification of plasma membrane structures involved in exocytosis, Proc Nat Acad $\mathrm{Sci}$ USA 94 (1997), 316-321.

[99] R. Bischoff, G. Bischoff and S. Hoffmann, Scanning force microscopy observation of tumor cells treated with hematoporphyrin IX derivatives, Ann Biomed Eng 29 (2001), 1092 1099

[100] M.A. Horton, G. Charras, C. Ballestrem and P. Lehenkari, Integration of atomic force and confocal microscopy, Single Mols 1 (2000), 135-137.

[101] N. Kataoka, K. Iwaki, K. Hashimoto, S. Mochizuki, Y. Ogasawara, M. Sato, K. Tsujioka and K. Fumihiko, Measurements of endothelial cell-to-cell and cell-to-substrate gaps and micromechanical properties of endothelial cells during monocyte adhesion, Proc Natl Acad Sci USA 99 (2002), $15638-15643$.

[102] M. Sato, K. Nagayama, N. Kataoka, M. Sasaki and K. Hane, Local mechanical properties measured by atomic force microscopy for cultured bovine endothelial cells exposed to shear stress, J Biomech 33 (2000), 127-135.

[103] J.A. Dvorak and E. Nagao, Kinetic analysis of the mitotic cycle of living vertebrate cells by atomic force microscopy, Exp Cell Res 242 (1998), 69-74.

[104] R. Matzke, K. Jacobson and M. Radmacher, Direct, highresolution measurement of furrow stiffening during division of adherent cells, Nature Cell Biol 3 (2001), 607-610.

[105] A.M. Collinsworth, S. Zhang, W.E. Kraus and G.A. Truskey, Apparent elastic modulus and hysteresis of skeletal muscle cells throughout differentiation, Am J Physiol Cell Physiol 283 (2002), C1219-C1227. 
[106] A.B. Mathur, G.A. Truskey and W.M. Reichert, Atomic force and total internal reflection fluorescence microscopy for the study of force transmission in endothelial cells, Biophys $J \mathbf{7 8}$ (2000), 1725-1735.

[107] Y. Yamane, H. Shiga, H. Haga, K. Kawabata, K. Abe and E. Ito, Quantitative analyses of topography and elasticity of living and fixed astrocytes, J Electron Microsc 49 (2000), $463-471$.

[108] J. Domke, S. Dannohl, W.J. Parak, O. Muller, W.K. Aicher and M. Radmacher, Substrate dependent differences in morphology and elasticity of living osteoblasts investigated by atomic force microscopy, Colloids Surf B Biointerfaces 19 (2000), 367-379.

[109] C. Rotsch, F. Braet, E. Wisse and M. Radmacher, AFM imaging and elasticity measurements on living rat liver macrophages, Cell Biol Int 21 (1997), 685-696.

[110] H.W. Wu, T. Kuhn and V.T. Moy, Mechanical properties of L929 cells measured by atomic force microscopy: effects of anticytoskeletal drugs and membrane crosslinking, Scanning 20 (1998), 389-397.

[111] W.H. Goldmann, R. Galneder, M. Ludwig, W. Xu, E.D. Adamson, N. Wang and R.M. Ezzell, Differences in elasticity of vinculin-deficient F9 cells measured by magnetometry and atomic force microscopy, Exp Cell Res 239 (1998), 235-242.

[112] E.L. Elson, Cellular mechanics as an indicator of cytoskeletal structure and function, Annu Rev Biophys Biophys Chem 17 (1988), 397-430.

[113] G. Langanger, M. Moeremans, G. Daneels, A. Sobieszek, M. De Brabander and J. De Mey, The molecular organization of myosin in stress fibers of cultured cells, J Cell Biol 102 (1986), 200-209.

[114] G.E. White and K. Fujiwara, Expression and intracellular distribution of stress fibers in aortic endothelium, $J$ Cell Biol 103 (1986), 63-70.

[115] O. Thoumine and A. Ott, Comparison of the mechanical properties of normal and transformed fibroblasts, Biorheology 34 (1997), 309-326.

[116] M. Lekka, P. Laidler, J. Ignacak, M. Labedz, J. Lekki, H. Struszczyk, Z. Stachura and A.Z. Hrynkiewicz, The effect of chitosan on stiffness and glycolytic activity of human bladder cells, Biochim Biophys Acta 1540 (2001), 127-136.

[117] A.L. Weisenhorn, P. Maivald, H.-J. Butt and P.K. Hansma, Measuring adhesion, attraction, and repulsion between surfaces in liquids with an atomic force microscope, Phys Rev B 45 (1992), 11226-11232.

[118] H.-J. Butt, P. Siedle, K. Seifert, K. Fendler, T. Seeger, E. Bamberg, A.L. Weisenhorn, K. Goldie and A. Engel, Scan speed limit in atomic force microscopy, J Microsc $\mathbf{1 6 9}$ (1993), 75-84.

[119] W.F. Heinz, M.D. Antonik and J.H. Hoh, Reconstructing local interaction potentials from perturbations to the thermally driven motion of an atomic force microscope cantilever, $J$ Phys Chem B 104 (2000), 622-626.

[120] M. Despont, H. Takahashi, S. Ichihara, Y. Shirakawabe, N. Shimizu, A. Inoue, W. Häberle, G.K. Binnig and P. Vettiger, Dual-cantilever AFM probe for combining fast and coarse imaging with high-resolution imaging, Thirteenth IEEE International Conference on MEMS January 23-27, 2000, 126131.

[121] M.R. Zile, R. Tanaka, J.R. Lindroth, F. Spinale, B.A. Carabello and I. Mirsky, Left ventricular volume determined echocardiographically by assuming a constant left ventricular epicardial long-axis/short-axis dimension ratio throughout the cardiac cycle, J Am Coll Cardiol 20 (1992), 986-993.

[122] D. Stamenovic and M.F. Coughlin, A quantitative model of cellular elasticity based on tensegrity, J Biomech Eng 122 (2000), 39-43.

[123] B.J. Briscoe, K.S. Sebastian and M.J. Adams, The effect of indenter geometry on the elastic response to indentation, $J$ Phys D: Appl Phys 27 (1994), 1156-1162.

[124] H. Lang, R. Berger, C. Andreoli, J. Brugger, M. Despont, P. Vettiger, C. Gerber, J. Gimzewski, J. Ramseyer, E. Meyer and H.-J. Güntherodt, Sequential position readout from arrays of micromechanical cantilever sensors, Appl Phys Lett $\mathbf{7 2}$ (1998), 383-385.

[125] S. Minne, J. Adams, G. Yaralioglu, S. Manalis, A. Atalar and C. Quate, Centimeter scale atomic force microscope imaging and lithography, Appl Phys Lett 73 (1998), 1742.

[126] J. Adams, G. Priyadarshan, A. Mabogunje, L. Leifer, C. Quate, E. Ong and B. Ramakrishna, Taking atomic force microscope advances to the university classroom. in Aerospace Conference, 2001, IEEE Proceedings 7 (2001), 3673-3682.

[127] D.E. Ingber, Tensegrity: the architectural basis of cellular mechanotransduction, Annu Rev Physiol 59 (1997), 575-599.

[128] T. Ohashi, Y. Ishii, Y. Ishikawa, T. Matsumoto and M. Sato, Experimental and numerical analyses of local mechanical properties measured by atomic force microscopy for shear endothelial cells, Biomed Mater Eng 12 (2002), 319-327.

[129] F. Jamitzky, R.W. Stark, W. Bunk, S. Thalhammer, C. Räth, T. Aschenbrenner, G.E. Morfill and W.M. Heckl, Scalingindex method as an image processing tool in scanning-probe microscopy, Ultramicroscopy 86 (2001), 241-246.

[130] W. Heisenberg, Physics and Philosophy: The Revolution in Modern Science, New York: Harper, 1958, 206. 


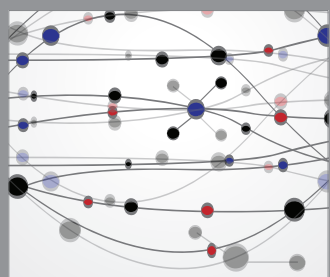

The Scientific World Journal
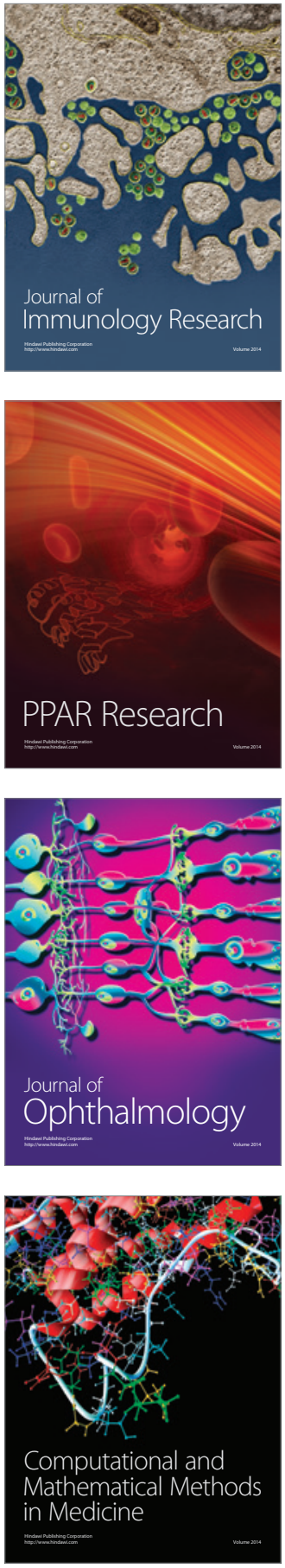

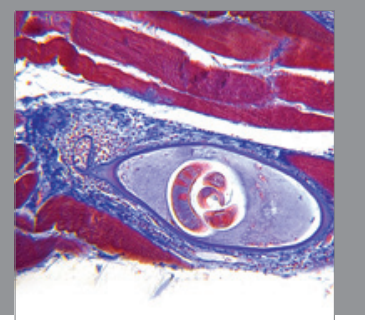

Gastroenterology

Research and Practice
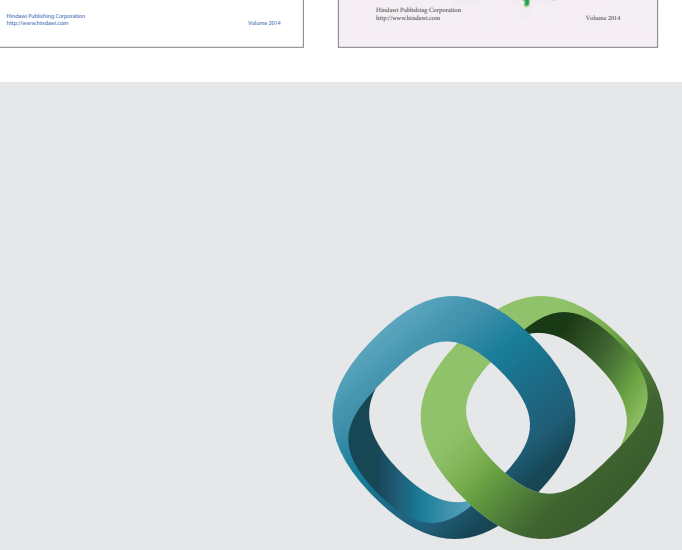

\section{Hindawi}

Submit your manuscripts at

http://www.hindawi.com
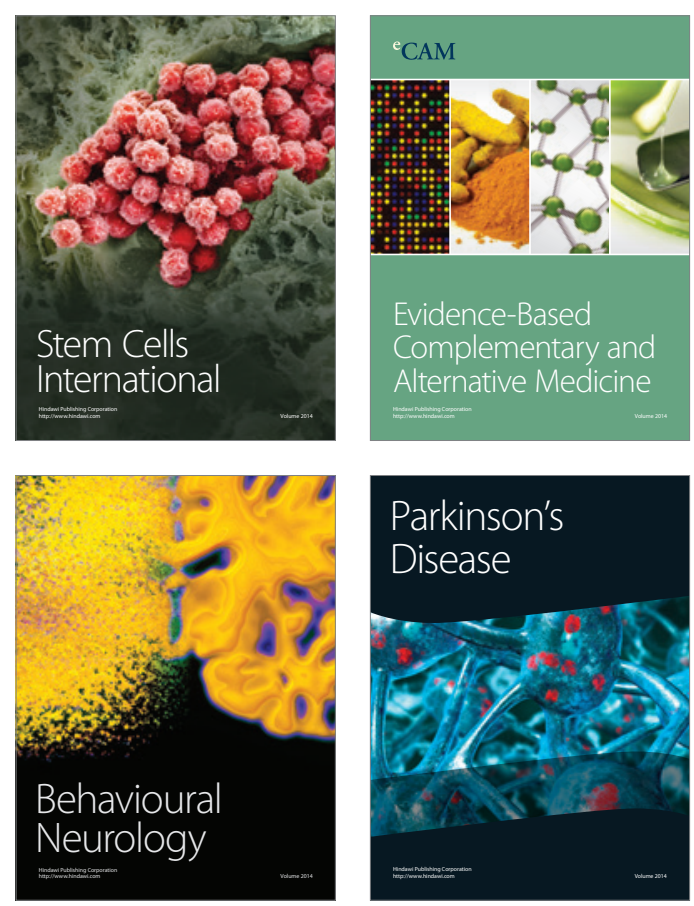

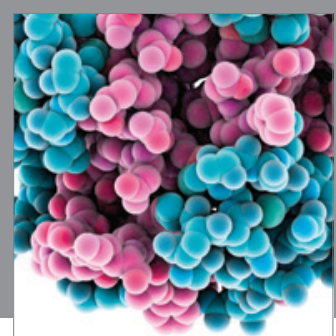

Journal of
Diabetes Research

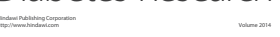

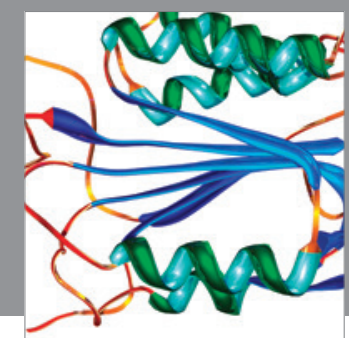

Disease Markers
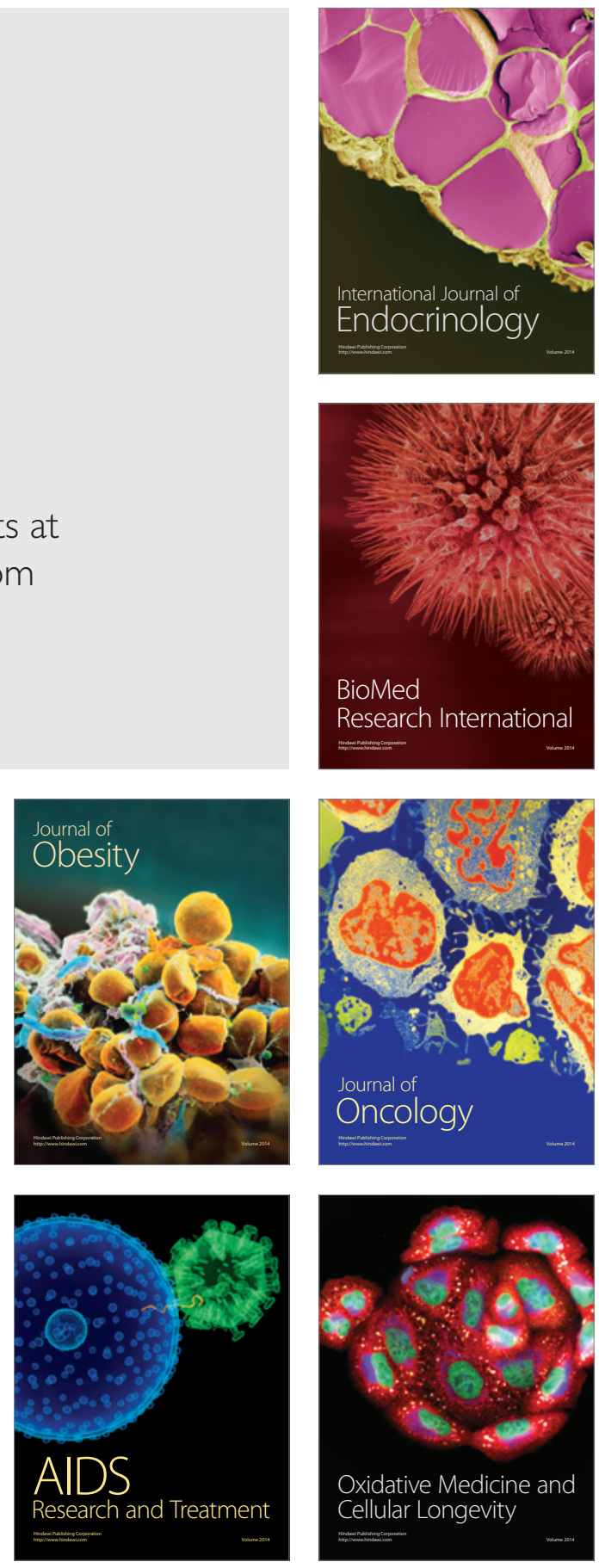